\title{
Understanding families' motivations for sustainable behaviors
}

\author{
Mary L. Barreto $^{\mathrm{a}, *}$, Agnieszka Szóstek ${ }^{\mathrm{b}}$, Evangelos Karapanos ${ }^{\mathrm{a}}$, Nuno J. Nunes ${ }^{\mathrm{a}}$, Lucas Pereira ${ }^{\mathrm{a}}$, \\ Filipe Quintal ${ }^{\mathrm{a}}$
}

${ }^{a}$ University of Madeira - MITI (Madeira Interactive Technologies Institute), Caminho Penteada, 9020-105 Funchal, Portugal

${ }^{\mathrm{b}}$ School of Form, ul. Glogowska 18, Poznan, Poland

\section{A R T I C L E I N F O}

\section{Article history:}

Available online 17 August 2014

\section{Keywords:}

Sustainability

Motivations

Behavior change

Family dynamics

Energy consumption

Eco-feedback

\begin{abstract}
A B S T R A C T
While interest in eco-feedback technologies has peaked over the last decade, research increasingly highlights that simply providing information to individuals regarding their consumption behaviors does not guarantee behavior change. This has lead to an increasing body of work that attempts to characterize individuals' latent motivations that drive sustainable behaviors. With this paper we aim at expanding this body of work by analyzing such motivations in the context of families. We report findings from interviews with 15 families who used an eco-feedback interface over a period of 2 years. Our study reveals that motivations for sustainable behavior were not only rooted in individuals' environmental concerns and need for expense management but they also regarded: (i) individuals' and families' need for a sense of control and security, (ii) parents' self-perceived responsibility of their role as parents and (iii) the perception of individual as well as family identity. We argue that in order for eco-feedback technologies to attain long-lasting behavioral changes in the domestic environment they need to address basic family needs that go beyond individual ideals of pro-environmental behavior.
\end{abstract}

(c) 2014 Elsevier Ltd. All rights reserved.

\section{Introduction}

Environmental threats and climate change have affected populations across the planet causing an impact on their health, access to resources and compromising the future generations (Abrahamse, Steg, Vlek, \& Rothengatter, 2005; Elias, Dekoninck, \& Culley, 2007; Froehlich, Findlater, \& Landay, 2010; Watterson \& Fernandez, 2012). The impact of these threats has brought together researchers and governments in the design and implementation of possible solutions towards sustainability. Researchers from the fields of sociology, psychology and economics have suggested that providing relevant information that facilitates awareness of consumption behaviors is likely to influence pro-environmental practices (Riche, Dodge, \& Metoyer, 2010). As a result campaigns evolved around the premise to promote environment-friendly behaviors within contexts involving domestic consumption, work related behaviors, public spaces and local communities (Froehlich et al., 2010, 2012). In this trait, most research domains centered on an individual as a decision maker (Wilson \& Dowlatabadi,

\footnotetext{
* Corresponding author. Tel.: +351 968156 768; fax: +351 291721006 .

E-mail addresses: mary.barreto@m-iti.org, maryluizbarreto@gmail.com (M.L. Barreto), aga.szostek@gmail.com (A. Szóstek), ekarapanos@uma.pt (E. Karapanos), njn@uma.pt (N.J. Nunes), lucas.pereira@m-iti.org (L. Pereira), filipe. quintal@m-iti.org (F. Quintal).
}

2007). Despite this general trend some sociologists questioned the relevance of the individually framed decision models and emphasized the social and technological construction of behavior (Wilson \& Dowlatabadi, 2007).

Research within the field of Human-Computer Interaction has focused on the so-called eco-feedback technologies, ones that sense and visualize energy consumption with the goal of promoting behavior change (Dillahunt, Mankoff, Paulos, \& Fussel, 2009; Elias et al., 2007; Froehlich et al., 2010). Research in eco-feedback technologies, up until now, has largely focused on changing individual behavior through psychologically grounded principles derived from theories of motivation and behavior change (e.g. (Abrahamse et al., 2005; Froehlich et al., 2010; He, Greenberg, \& Huang, 2010; Petkov, Goswani, Kobler, \& Kremar, 2012; Petkov, Köbler, Foth, \& Krcmar, 2011). However, concerns regarding the long-term impact of persuasive designs are increasing (Broms et al., 2010; Pierce, Schiano, \& Paulos, 2010; Strengers, 2011) and researchers call for an emphasis on how eco-feedback technologies should integrate with the cultural and social practices (Horn et al., 2011; Strengers, 2011).

Particularly, domestic practices have attracted an increased interest, both due to the uniqueness and complexity of such an environment, but also because of its substantial contribution to $\mathrm{CO}_{2}$ emissions (Davidoff, Lee, Yiu, Zimmerman, \& Dey, 2006; Watterson \& Fernandez, 2012). As such, households have been 
characterized as an ideal target for the design and evaluation of new eco-feedback technologies (Strengers, 2011; Watterson \& Fernandez, 2012). Still, the implemented interventions have so far failed to endure in the long term, calling researchers' attention into the ways in which eco-feedback technologies integrate with domestic activities and social norms (Strengers, 2011; Woodruff, Hasbrouck, \& Augustin, 2008).

As a result, a number of researchers have started studying individuals' motivations for pro-environmental behaviors in the domestic place. The most frequent motivations have been found to relate to individuals' need for cost management, to environmental concerns or values (Dillahunt et al., 2009; Pierce, Schiano, et al., 2010; Strengers, 2011). However, it is crucial to realize that families often experience difficulties when implementing eco-friendly practices due to the diversity regarding its members, in particular, in terms of age, needs, daily habits, schedules and comfort levels (Froehlich et al., 2010; Horn et al., 2011; Odom, Pierce, Stolterman, \& Blevis, 2009; Pierce, Fan, Lomas, Marcus, \& Paulos, 2010; Strengers, 2011). Such an observation indicates that ecofriendly practices are negotiated within the household rather than imposed (Horn et al., 2011; Pierce, Schiano, et al., 2010; Strengers, 2011). Researchers found that some practices are non-negotiable once a family believes to be doing everything in their power to reduce their energy consumption (Pierce, Fan, et al., 2010; Strengers, 2011). In other cases, however, having access to ecofeedback fails to challenge the existing practices, or even becomes used as a guideline to keep the consumption levels stable throughout time although such levels are neither low nor efficient (Pierce, Fan, et al., 2010; Strengers, 2011).

Based on the related work we argue that getting a better understanding of the complex structure of families' motivations for proenvironmental behaviors can provide a useful guide for the design of more effective technological solutions. We report interviews with 15 families who used an eco-feedback interface for 2 years. Our goal is to understand how latent motivations of the different family members shaped and regulated their sustainable practices.

This paper organizes as follows; first we present the related work introducing how the literature review has analyzed motivations for sustainable behaviors, then the research motivation and the techniques used to collect the data about family's motivations within this study. The findings are then explained in terms of previous literature but also, group differences. Finally, the discussion and conclusions reflect on the current results and how can these be integrated to address family's specific needs.

\section{Related work}

Pro-environmental behaviors are driven by a wide range of latent needs and motivations. Within $\mathrm{HCl}$, researchers have found such motivations to tap into individual needs for managing life costs (Chetty, Tran, \& Grinter, 2008; Davidoff, Ziebart, Zimmerman, \& Dey, 2011; Miller \& Buys, 2010; Steg, 2008; Tan, 2009), achieving and maintaining comfort levels (Chetty et al., 2008), and acting according to environmental concerns (Schäfer \& Bamberg, 2008). Eco-friendly behaviors are further driven by established habits and routines (Gram-Hassen, 2007; Hazas, Friday, \& Scott, 2010; Steg, 2008; Strengers, 2011), social influences (Petkov et al., 2011; Thieme et al., 2012) and through an attempt to display conformance to one's own self-identity (Black \& Cherrier, 2010; Gronhoj, 2006).

Financial motivations are often the most salient ones in initial interactions with eco-feedback technologies. As such, many ecofeedback interfaces have been designed with the goal of providing ways to control households' energy costs (Chetty et al., 2008; Kjeldskov, Skov, Paay, \& Pathmanathan, 2012; Tan, 2009). Such motivations are understood as basic since they tap to individuals' concerns over their economic sustainability (Dillahunt et al., 2009). Information on energy consumption has often proven useful in challenging individuals' misconceptions on the long-term energy costs of devices and established ill habits (Chetty et al., 2008; Kjeldskov et al., 2012; Tan, 2009). However, research has also showed that increasing awareness about energy costs does not necessarily imply a change in people's behavior (Pierce, Schiano, et al., 2010; Shove, 2010). Moreover, not all family members share financial motivations to the same extent, as, habitually, only one or a subset of them is responsible, or even aware, of a need to control energy costs (Chetty et al., 2008).

Another motivation regarding eco-friendly behaviors is the level of comfort families desire regardless of its environmental impact (Chetty et al., 2008; Dillahunt et al., 2009; Hazas et al., 2010; Kappel \& Grechenig, 2009; Steg, 2008). Families who referred to this motivation, wanted, for instance, to control the thermostat to be able to maintain comfortable temperature at all times. They also tended to maintain their meat consumption without considering other food alternative and, preferred to have access to transportation at all times, either through owning two cars or buying a larger one to drive all family members regardless of fuel efficiency.

Yet another motivation for sustainable behaviors regarded the need to maintain daily routines and habits (Dillahunt et al., 2009; Gronhoj, 2006; Pierce, Schiano, et al., 2010). According to Schafer et al. (Schäfer \& Bamberg, 2008) habits are responsible for the establishment of repeated behaviors and work as conservative forces where new information about alternative behaviors is considered. Habits, therefore, seem to restrict behaviors and render some modifications as non-negotiable by constraining individual flexibility to change (Pierce, Fan, et al., 2010; Pierce, Schiano, et al., 2010; Strengers, 2011). For instance, habits learned from previous generations, which found them convenient, efficient and useful, such as e.g. doing laundry at $60 \mathrm{deg}$, which can be seen as essential to guarantee $100 \%$ clean clothes, are difficult to give up (Gram-Hassen, 2007; Hazas, Brush, \& Scott, 2012; Strengers, 2011).

Sustainable behaviors can also be driven by environmental concerns. It has been shown that people are concerned about future generations' access to resources, and, for that reason, are willing to modify their lifestyles and surroundings to address these concerns (Chetty et al., 2008; Dillahunt et al., 2009). Individuals driven by such a motivation are more likely to be mindful about their consumption behaviors and change their daily routines (Gilg, Barr, \& Ford, 2005; Miller \& Buys, 2010; Woodruff et al., 2008). For example, they may repair old appliances, attempt to reduce electricity usage through engaging in outdoor activities, replace plastic with cloth bags, shop in local markets, reuse water from the shower to water plants or use an extra sweater in the house instead of increasing the heating temperature (Chetty et al., 2008; Gilg et al., 2005). As seen in Fransson and Garling (1999) these individuals possess a considerable level of knowledge about environmental problems, are willing to discuss alternative solutions and develop skills to achieve intended behaviors.

It has been further found that individuals' social network exert influence on their energy consumption. For instance, individuals are more willing to modify behaviors when the impact of these behaviors becomes visible to their social network (Froehlich et al., 2010; Petkov et al., 2011; Pierce, Fan, et al., 2010; Thieme et al., 2012). While social influences take place in a number of ways such as peer pressure, public accountability and competition (Froehlich et al., 2010; Pierce, Fan, et al., 2010), central to all these is the notion of self-identity (Belk, 1988; Zimmerman, 2009) For instance, some people are driven by anti-consumption practices (i.e., reducing, reusing and rejecting the purchase of new products whenever possible) (Black \& Cherrier, 2010). Within these anticonsumption contexts, individual values and self-perception are driving individual acts which often tap to one's social responsibil- 
ity, sense of involvement, personal fulfillment and social belonging (Black \& Cherrier, 2010; Gilg et al., 2005).

The diversity of motivations suggests that individuals' ecofriendly behaviors are constrained by one's circumstances, social context and access to resources (Strengers, 2011). While one would expect that individual motivations could be predicted by a limited number of factors, such as one's level of income, research confirms that this is not the case (Froehlich, 2009). For instance, even for low-income communities green behaviors may be motivated by spiritual and self-actualization concerns (e.g., moral aversion to waste) or a sense of duty to protect the environment for future generations (Dillahunt et al., 2009; Fransson \& Garling, 1999; Riche et al., 2010).

In that context we set out to investigate how the motivations stimulating eco-friendly behavior differ between three different types of families, namely: families without children, with young children and with older children. Our goal was twofold. We wanted to show that in order to stimulate sustainable behaviors it is necessary to design for families rather than individuals and also that the offered technologies need to be adjustable to the changing needs of the different types of families and also to the different stages of their lives.

\section{Research motivation}

Recent studies have suggested that addressing sustainable behaviors should include major areas of impact such as indoor climate, travel, food and buying behavior (Hazas et al., 2012). Sustainability analysis implies then, a much larger focus as people might adopt behaviors that are not always a result of their individual choices but are integrated into various contexts and exposed to social dynamics (Brynjarsdóttir et al., 2012; Hazas et al., 2012; Shove, 2010). Sustainable behaviors should then be analyzed on different levels by cataloging behaviors people consider as essential, understanding various motivations and their impact or consequences within their context while considering how social ties influence individual choices (Dillahunt et al., 2009; Hazas et al., 2012; Strengers, 2011). Since families can be seen as groups among which multiple motivations naturally emerge, it is fundamental to know what drives their actions as a group, and how they integrate change in their natural context. Analyzing the home space is fundamental to understand the roles of family members, their responsibilities, negotiation processes and priorities, and how all these relate to the individual motivations. Since this analysis can help to structure the design of technologies that help to pursue longterm eco-friendly behaviors.

In this context, our research aimed to understand what motivations concerning sustainable behavior family's express, how these motivations are negotiated and how they co-evolve in different contexts. We organize our findings around the following questions:

- What are family's motivations for sustainable behaviors and how do they compare to previous studies?

- How do these motivations differ between family type: families with or without children, and families with younger and older children?

- Are there differences between family types and interaction with the eco-feedback system used to probe families about energy consumption practices?

\subsection{Eco-feedback technology}

The families that participated in our study had been using an eco-feedback technology aimed at monitoring and providing feedback on families' energy consumption practices. The technology consisted of a low/cost, single point, nonintrusive load monitoring sensing infrastructure implemented in software and deployed in a netbook. The netbook was installed next to the mains fuse box, which in all participants' apartments was located in the main corridor, a place that we judged appropriate for a public display (see Fig. 1). The eco-feedback interface was displayed in the netbook and presented information relating to the household's overall consumption per day, week or month, and in terms of $\mathrm{kW} \mathrm{h}$, cost, and $\mathrm{CO}_{2}$ emissions (see Fig. 1, for a more elaborate description of the system see Anonimized for review 2012). The system acted as a technology probe (Anonimized for review 2005) aimed to sensitize families about their energy consumption practices.

\subsection{Participants}

This study was conducted in a city, which is the capital of a Portuguese island with a total of 267,785 million people. The participants for this study were chosen from an overall city consumption database (about 50,000 consumers). The research team selected a set of apartment buildings that corresponded to the average city consumption pattern from the referred database. The apartment buildings were located in a neighborhood composed mostly by Caucasian families and working people. A number of 30 families from that building volunteered for the study. Out of the initial group, a number of 15 families further volunteered to participate in the interview study. The families lived in their homes for approximately 6 years, with the minimum time 2 years and the maximum 11 years $(M=6.25, \mathrm{SD}=2.59)$. Their homes were apartments with one up to three bedrooms. Overall the sample of participants belonged to lower and middle socio-economical class (see Table 1 for more details). We divided the sample into three groups: (A) families with young children under age of 10 years; (B) families with children older than 10 years; and (C) families without children (see Table 1 for more details). Group B included children under 10, and were integrated in this group based on the age of the oldest child. Such a division was motivated by previous studies suggesting that families address consumption concerns differently when younger children (Gronhoj, 2006) or teenagers are involved (Gram-Hassen, 2007).

\subsection{Method}

The study involved in-situ interviews with the entire family. We opted to have all family members present, as we wanted to see how they interacted with each other when addressing energy consumption issues. The interviews were semi-structured and consisted of a warm-up discussion where we probed for general information relating to family daily routines, their concerns and their expenses with utilities. It was followed by reflective interviewing on the aspects of energy conservation practices they had performed in the past. Interviews lasted from 45 to $90 \mathrm{~min}$. They were videotaped and transcribed for analysis.

Data were content analyzed using Hsieh and Shannon's traditional qualitative content analysis (Hsieh \& Shannon, 2005) following a three-step process. The two initial steps aimed to respond to the following question: what are family's motivations for sustainable behaviors and how do they compare to previous studies?

In the first step, the interview transcripts were processed to identify concepts that expressed individual motivations for proenvironmental behavior using the NVivo software tool (International, 2012). In the second step, we used affinity diagrams (Beyer \& Holtzblatt, 1998) where the initial themes were contrasted to individuals' motivation for pro-environmental behaviors as reported in literature e.g., (Broms et al., 2010; Chetty et al., 2008; Gilg et al., 2005; Woodruff et al., 2008). The affinity diagrams were used by the research team members as brainstorm techniques to support the classification of participants' quotes into 

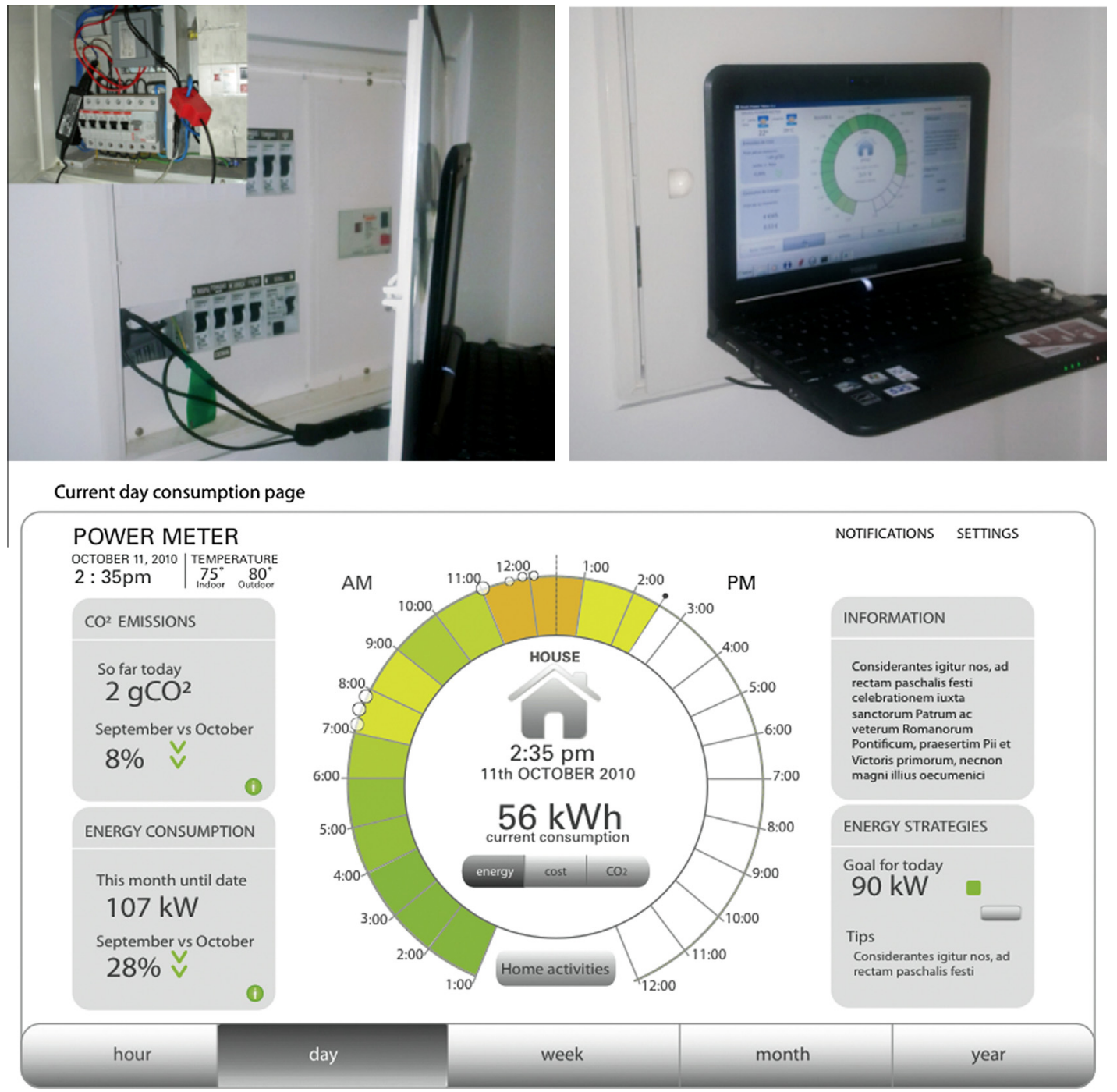

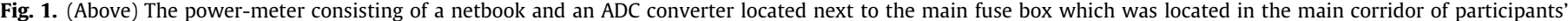

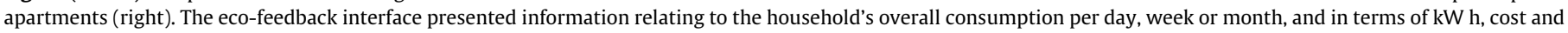
$\mathrm{CO}_{2}$ emissions (below).

\section{Table 1}

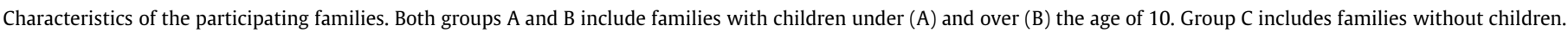

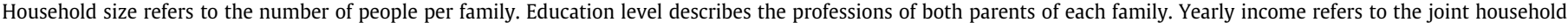
income.

\begin{tabular}{|c|c|c|c|c|}
\hline Family ID & Children (ages) & Household size & Educational level (father/mother profession) & Yearly income $(€)$ \\
\hline \multicolumn{5}{|l|}{ Group A } \\
\hline 1 & $2(5,10)$ & 4 & Electrician/Kindergarten Teacher & $40 \mathrm{k}-50 \mathrm{k}$ \\
\hline 2 & $1(1)$ & 3 & Seller/Teacher & $40 \mathrm{k}-50 \mathrm{k}$ \\
\hline 3 & $2(1,7)$ & 4 & Security Guard/Supermarket clerk & $0-5 \mathrm{k}$ \\
\hline 4 & $2(1,5)$ & 4 & Electrical Engineer/Biologist & $100 \mathrm{k}-250 \mathrm{k}$ \\
\hline 5 & $2(2,4)$ & 4 & Arts Teacher (both) & $50 \mathrm{k}-100 \mathrm{k}$ \\
\hline 6 & $1(3)$ & 3 & Nurse/Doctor & $40 \mathrm{k}-50 \mathrm{k}$ \\
\hline \multicolumn{5}{|l|}{ Group B } \\
\hline 7 & $1(10)$ & 4 & Policeman/Secretary & $19 \mathrm{k}-27.5 \mathrm{k}$ \\
\hline 8 & $2(7,14)$ & 5 & Music Teacher/Nurse & $27.5 \mathrm{k}-32.5 \mathrm{k}$ \\
\hline 9 & $2(13,15)$ & 4 & Architect/Travel Agent & $50 \mathrm{k}-100 \mathrm{k}$ \\
\hline 10 & $2(7,11)$ & 4 & Businessman/Sociologist & $50 \mathrm{k}-100 \mathrm{k}$ \\
\hline 11 & $1(15)$ & 3 & Unemployed/Kindergarten Teacher & $19 \mathrm{k}-27.5 \mathrm{k}$ \\
\hline \multicolumn{5}{|l|}{ Group C } \\
\hline 12 & 0 & 2 & Manager/College Student & $10 \mathrm{k}-13.5 \mathrm{k}$ \\
\hline 13 & 0 & 2 & Croupier/College Student & $5 \mathrm{k}-10 \mathrm{k}$ \\
\hline 14 & 0 & 2 & Designer/Hotel Manager & $27.5 \mathrm{k}-32.5 \mathrm{k}$ \\
\hline 15 & 0 & 2 & Accountant/Lawyer & $40 \mathrm{k}-50 \mathrm{k}$ \\
\hline
\end{tabular}


Table 2

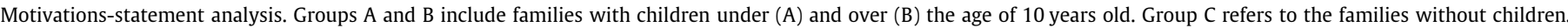

\begin{tabular}{|c|c|c|c|c|}
\hline \multirow[t]{2}{*}{$\begin{array}{l}\text { Motivations } \\
\text { (total) }\end{array}$} & \multicolumn{3}{|c|}{$\begin{array}{l}\text { Number } \\
\text { of quotes } \\
\text { per group }\end{array}$} & \multirow[t]{2}{*}{ Examples } \\
\hline & A & B & $\mathrm{C}$ & \\
\hline Identity (16) & 7 & 6 & 3 & "My wife does not care about this, I am the one doing this" (family 4, Father) \\
\hline Costs (14) & 5 & 5 & 4 & $\begin{array}{l}\text { "Even with the kids, they are not always careful (...) things are not cheap nowadays we cannot afford to spend too much or spend excessively" } \\
\text { (family } 1, \text { Mother) }\end{array}$ \\
\hline Parenting (12) & 7 & 5 & 0 & "We have a small child (3 year old) and we tell her to switch off the lights. If we do these things we know she will imitate us" (family 6, Mother) \\
\hline Routines (7) & 3 & 4 & 0 & "I am aware but I will not stop using things because they are (...) basic activities of the day" (family 9, Father) \\
\hline $\begin{array}{l}\text { Sense of control } \\
\text { (5) }\end{array}$ & 2 & 2 & 1 & $\begin{array}{l}\text { "I have the devices all grouped to be unplugged with a remote (...) I read somewhere these allowed us to save around } 30 \text { euros a year" (family } \\
14, \text { Husband) }\end{array}$ \\
\hline Environment (3) & 1 & 1 & 1 & "I think the environmental impact is important and I talk to my kids about it" (family 10, Mother) \\
\hline
\end{tabular}

themes that would fit previous motivations or new motivations that emerged within the family context. The quotes referred to specific statements from the interviews. We compared the motivations found on previous studies with the ones reported by the families in the current study.

In the third step, we performed a comparative analysis of the motivations by the three groups of families (see Table 2 for more detail) guided by the following question: how do motivations differ between family type: families with or without children, and families with younger and older children? In this analysis we grouped sets of relevant statements or quotes that participants shared with the research team in the interviews, into higher-level categories and verified the differences in terms of family characteristics and their motivations to pursue and adopt sustainable behaviors. In addition we looked into the differences in terms of interaction with the eco-feedback system and family type.

\section{Findings}

This section presents findings in two parts: firstly we describe motivations guiding families in their sustainable behaviors and secondly we compare the impact of these motivations between the three family types. Some motivations for sustainable behaviors tapping into the need of controlling energy costs, concerns about the environmental impact and routines and everyday practices are known from the related literature. Our research has further identified a additional set of themes that referred to individuals' and families' need for a sense of control and security, parents' self-perceived responsibility over their role as parents and the perception of self as well as family identity (for more details see Fig. 2). In addition, we present a quantitative analysis of differences, according to family type, in terms of interaction with the system and energy consumption levels.

\subsection{Comparative analysis: family's motivations for sustainable} behaviors and how do they compare to previous studies

\subsubsection{Costs and concern for the environment}

Froehlich (2009) found that users seemed to focus mostly on energy unit and cost when considering environmental impact, as they understand their relative magnitude and implications. Similarly, in our study participants often highlighted the relevance of reducing costs in their daily lives as opposed to thinking about environmental impact: "It is more the cost what affects us directly. If we talk about environmental impact we do not worry about it. As it does not affect us directly we do not think so easily about it" (family 7, Son, ref 4). A concern for the environment was often paired with other responsibilities such as making sure one's children would learn and understand implications of their consumption: "In the schools they learn about saving and being careful for the environment and at home we try to keep the same line of thought" (family 1, Mother, ref 1).

Participants mentioned that reducing costs was something "[they] deal directly and most frequently with" (family 7, Mother, ref 2). Costs were pervasive to all kinds of daily activities and families were frequently exposed to them, which made cost a salient cue with respect to energy consumption. Concerns related to costs seemed to be frequent for families but not equally considered by all its members due to reasons such as responsibilities and family roles: "We deal directly with the money, they [children] do not pay the bills" (family 7, Mother, ref 5).

\subsubsection{Routines}

Families organized their lives around routines: to complete their chores, tasks and goals and make sure their schedules were followed. The routines consisted of habits determining how they managed their household resources but also how they used electri-

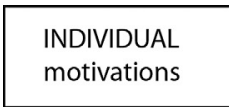

Reduce or control costs Comfort Habits

Environmental concerns Social Influences Identity

\section{FAMILY motivations}

Reduce or control costs Routines Environmental concerns $+$ Current study found motivations

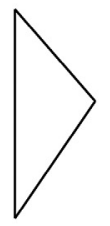

Sustainable Behavior

Self and Family Identity

Parenting

Sense of control

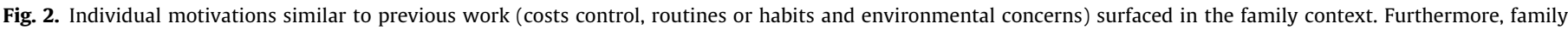
specific motivations emerged such as identity, parents' perceived responsibility on their roles as parents and family need for sense of control. 
cal appliances: "I feel I am using energy but I can not live by candlelight. . I use the energy I need, I have the television on because I need her (her daughter) to be entertained. I think I am only using the energy I need." (family 6, Mother, ref 3). It was a balance between expectations, needs and available resources: "I am aware but I will not stop using things (...) and those are all basic activities that I do not think consume too much, they are things that I need" (family 9, Father, ref 5). Use of devices and energy consumption was, therefore, a response to daily practices, an effort to manage different family expectations and most of the times a result of a habit (GramHassen, 2007; Hazas et al., 2010; Pierce, Fan, et al., 2010; Strengers, 2011).

\subsubsection{Sense of control}

When asked about the management of energy consumption families frequently shared measures they took to save energy, which led us to assume that families sought some sense of control of what they used: "I realized that the consumption of some things around the house even on stand-by was high so I went to a store where they had this kind of equipment and asked them what I could use to control this kind of stand-by consumption (...)" (family 5, Father, ref 3). Families revealed a need to know more about how much they used and how their behaviors and actions related to the consumption that was expressed in the utility bill in the same way as in He et al. (2010). Access to this information provided families with a sense of control.

\subsubsection{Parenting}

We noted that, similarly to Gronhoj (2006), parents' reflections upon energy consumption were often directed towards their children. We found three needs related to parenting:

Educating. Energy consumption was often seen as a means to communicate concepts that parents wanted their children to adopt such as expense and resource management: "They need to learn that we need to value the things we have" (family 10 Father, ref 7), "They are very distracted whenever they leave their rooms and leave the lights on (...) they go from room to room without paying attention to the lights" (family 1, Mother, ref 2).

Offering a role model. Parents tended to modify their behavior to set an example which helped them feel they were good parents: "As we have a small child if we tell her to turn off the light when she is not using it and if we do it she will do it too" (family 6, Mother, ref 1), "One of the things I do is charge these devices after $11 \mathrm{pm}$ and try to tell them to do the same" (family 10, Mother, ref 4).

Providing discipline. Enforcing sustainable behaviors was also used as a means towards exercising discipline towards children: "We have to tell him over and over to do it, whenever we go to the kitchen to have dinner" (family 1, Mother, ref 3), "They are used to this routine of only getting what we really need. If they want something, for example the youngest one, we try to negotiate" (family 10 , Mother, ref 8 ).

\subsubsection{Self and family identity}

The issues of self- and family-identity surfaced in our interviews with 8 out of the 15 families. Individual perceptions of self-identity were often triggered at the occasion of arising conflicts: "My wife does not care about this, I am the one doing this [turning off the lights and being careful about energy usagel" (family 4, Father, ref 3). Whereas, notions of family-identity were often induced by individuals attempting to motivate all members, especially children, in adopting sustainable behaviors either by monitoring their usage of appliances related to entertainment (television and computer), by using supermarket lists to teach them how to avoid superficial expenses or by avoiding having non-healthy food at home: "They are used to this routine of only getting what we really need. If they want something [...] we try to negotiate" (family 10, Mother, ref 8 ). In the case of four families, the values constructing the perception of family identity were inherited from previous generations and used as a trigger for reminiscence: "We did not say to ourselves we need to save energy, we already had this with us from our parent's home" (family 15 , Wife, ref 4 ).

\subsection{Comparative analysis within the family groups}

This section reports on the differences in the observed motivations as they surfaced in three different types of families (see Fig. 3). Motivations are listed in terms of frequency and relevant quotes are used to reflect and situate each type of motivation (see Table 2 for more detail). The quotes were statements extracted from the interviews conducted with the participants. The differences are analyzed bellowed in terms of each category.

\subsubsection{Costs and concern for the environment}

With respect to costs, the differences between the three groups were minimal - all families were motivated towards eco-friendly behaviors as a way of saving money, avoiding unnecessary expenses and reducing their consumption levels. The electricity bill at the end of each month was the trigger for this motivation: "We control the costs, especially if the bill is higher than usual, if it is more than 25 euros than that means something is wrong" (family 14, Husband, ref 2).

Environmental concerns were secondary for all three types of families. Yet, this motivation was interpreted differently among the different groups. For group A, the concern for the environment was seen as a part of parental responsibility to educate children from a young age about environmental values. Parents of older children attempted to integrate this particular motivation with other types of motivations, such as parenting and sense of control. For group $C$ such a motivation was the result of an intrinsic interest associated with spouses' own personality and lifestyle they chose to adopt.

\subsubsection{Routines}

In terms of group differences, routines differed according to each group's availability to either follow or change their habits. We found that routines were more rigid and inflexible among group A (families with children under the age of 10) when compared to group B (families with children older than 10 years old).

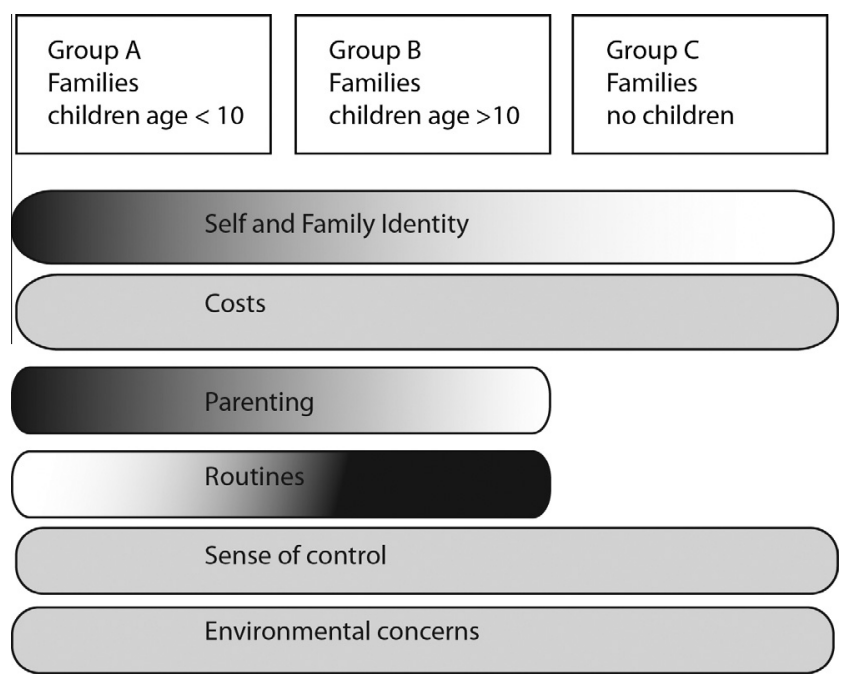

Fig. 3. Motivations displayed in terms of importance across family type. Darker areas demonstrate most important and higher frequency motivations. 
For group A, routines were something easy to fall out of parents' control, as parents with younger children had to deal with more unpredictable situations. On the other hand, group A families revealed less flexibility to change their routines to accommodate new behaviors. In fact, some routines were aspects of their lives families maintained at all costs, even if these were not perceived as environmental-friendly: "for example he is here with me (referring to the baby) I need to have the television on for a longer time before he was born the television wouldn't be running for so long" (family 2, Mother, ref 1). Nevertheless, these were conditions they needed to conduct their daily lives around the household, especially when younger children were involved. Routines worked as a motivation for these families depending on the children's circumstantial needs.

For families in group B, routines were sometimes built around special house constraints and became a motivation. For instance, in one case the apartment had limited natural light and the family could not avoid switching lights on: "We try to reduce here and there but this is an apartment we can not walk here in the darkness, we need to turn on some lights. When we are at home we spend more. It is not easy to reduce" (family 11, Mother, ref 1 ). At points, families from group B, reported perceiving routines as basic activities they needed to accomplish and thus, would not give up or even negotiate upon them: "No I do not feel guilty for using electricity (...) I am aware that I am using this energy (...) I do not feel guilty and will not stop using things" (family 9, Father, ref 6). While families that could control routines to some extent, they often did not want to (e.g. families with teenage children).

With respect to families in group C (families with no children), there was no mentioning of motivations tied to performing or managing daily routines. Families in this group justified their energy consumption with respect to personal efforts to control its level rather than external circumstances or factors that were out of their control: "It is our consumption, we do not make big efforts to be like that (low consumption), we do not use an external heater, we are careful about the kind of lamps we use at home" (family 15 , Husband, ref 1 ).

\subsubsection{Sense of control}

With respect to families' need for maintaining a sense of control, no differences were found among the three groups. All of them referred to measures they adopted to have a more accurate estimate of their energy consumption: "If we want to analyze in detail how much we spend in terms of energy I can do it because I have a device here that measures the appliances power (...) I know exactly how much I use and how much I spend" (family 4, Father, ref 2).

\subsubsection{Parenting, self and family identity}

We observed that group A and B referred more frequently to motivations that tapped to self and family-identity. For parents with younger children, motivations were based on the following needs: need to educate, be a role model and to discipline their children in terms of consumption practices. Additionally, parents' motivations were associated with the need to provide their children with a sense of family identity. The motivation regarding family identity stemmed from creating and communicating ideas and values to children, such as ones related to saving and resource management. For group B, motivations related to parenting were rated at the same level as the ones tapping into cost management. While group A referred to constant supervision of their children and feedback by correcting behaviors, group B expected their children to conduct sustainable practices autonomously. However, these expectations were not always materialized: "I chase them around to turn off the lights..." (family 8, Mother, ref 1 ).

\subsection{Comparing the groups in terms of consumption and system interaction}

The three groups were compared in terms of quantitative measures collected throughout the study, namely, interaction with the system and energy consumption levels. Overall, group B composed by families with children older than 10 years, was the one, which registered higher scores with respect to the referred variables.

The interaction with the system was measured through the number of mouse clicks users performed when manipulating the system. An analysis using Kruskal-Wallis test indicated significant differences between the three groups $(H(2)=20.773, p<.05)$. The group with the highest number of interactions (mean rank $=601.33$ ) was group B.

Energy consumption levels were measured in terms of reductions throughout the study (the number of weeks the families participated in the study) and in terms of total consumption in the same period (average of total consumption).

The three groups of families reduced their consumption throughout the study ( 89 weeks) (as illustrated by the trend line in Fig. 4). Group B, families with children over 10 years old, registered higher levels and peaks of consumption when compared with the two other groups throughout the duration of the study (see Fig. 4). From weeks 77 onwards the consumption levels drop in the graph was explained by the fact that a large part of the families were removed from the study.

Total consumption levels were significantly different for the three groups $(H(2)=511.476, p<.05)$. The group with highest total consumption levels was group B families with children older than 10 years (mean rank $=833.21$ ) as illustrated in Fig. 5 .

\section{Discussion and conclusion}

The goal of our study was to analyze eco-friendly motivations in the context of families. Similarly to prior work (Broms et al., 2010; Dillahunt et al., 2009; Pierce, Schiano, et al., 2010; Strengers, 2011), we noted that both financial as well as environmental concerns were often used as primary arguments in justifying sustainable behaviors. The combination of financial and environmental concerns was materialized through strategies and measures such as replacing old appliances or buying remotes to unplug stand-by devices. However, the level of awareness differed with respect to the role in the family, as family members were not all equally aware of cost implications or the environmental impact of their energy practices. This diversified awareness impacts motivations within the family, and explains why different family members might focus on different types of motivations. As a result when analyzing family context this is another variable to consider, how are motivations grounded within the family space. Moreover, the diversity of motivations across family members should be taken into account as different people are motivated in various ways (He et al., 2010). Furthermore, intentional behavior change evolves across a set of phases, where the level of awareness towards a specific behavior increases, ultimately reaching a number of conditions to change and maintain a desired behavior. Family members encounter themselves to be at different stages of such a behavior change. Thus, it is crucial to assess the level of individual mindset and commitment to adopt or invest in sustainable behaviors within the household before proposing adequate solutions. In line with the findings by Neustaedter, Bartram, and Mah (2013), we also observed that parents did not share information about their electricity bills with their children as they felt that bills were their responsibility and should not become their children's concern. In such a way the parents were unwillingly excluding their children from consumption related information and, conse- 


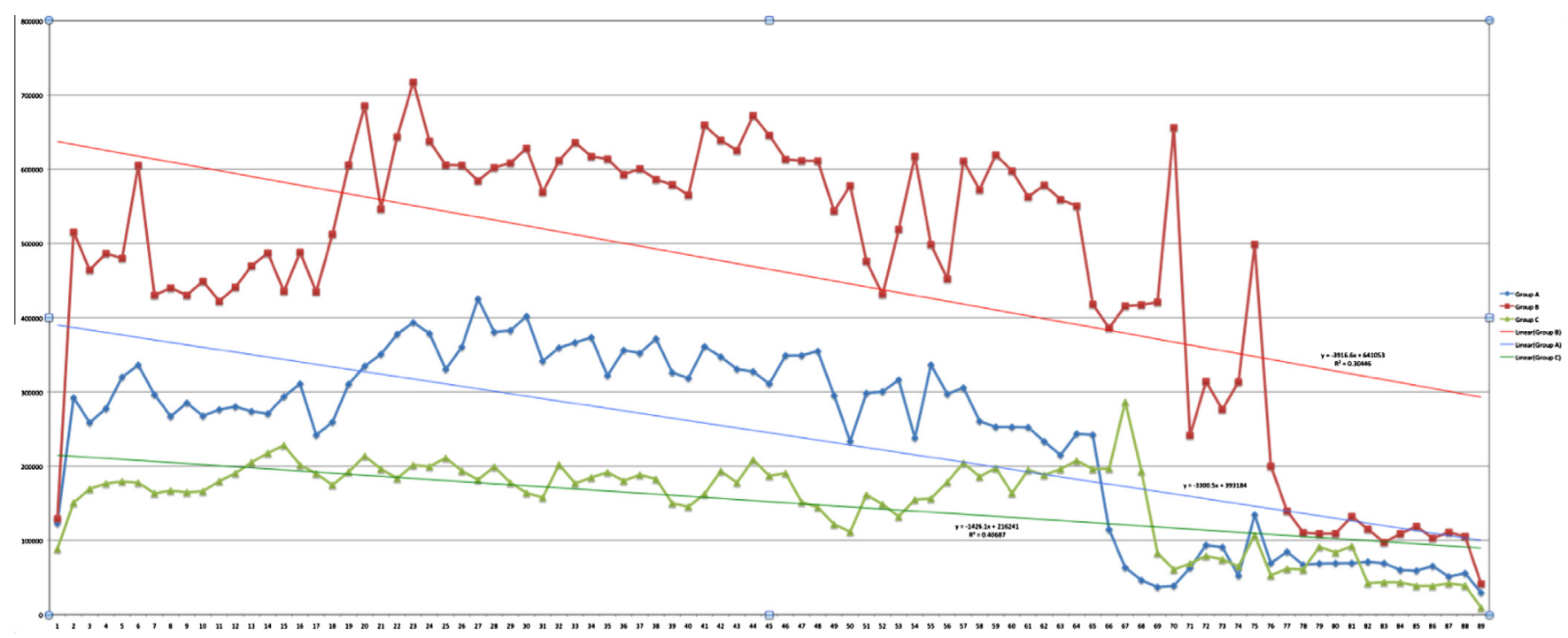

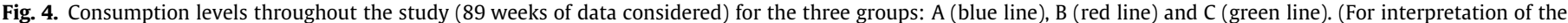
references to color in this figure legend, the reader is referred to the web version of this article.)

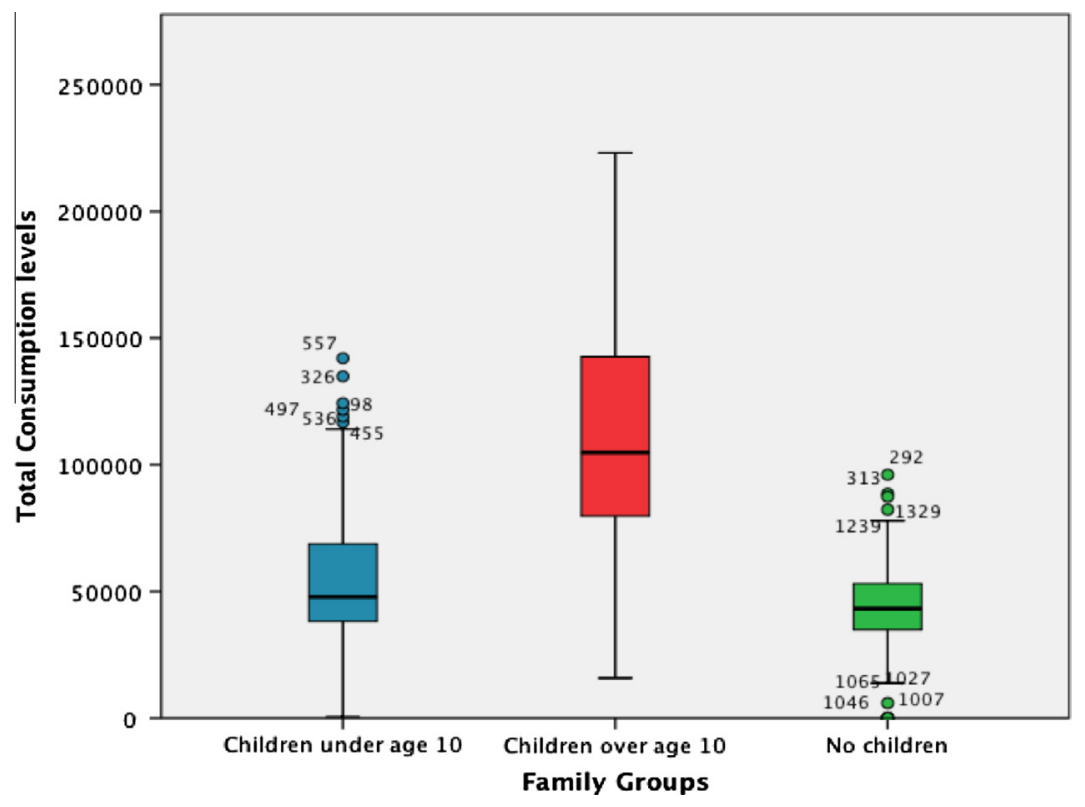

Fig. 5. Total consumption levels for three types of families.

quently, compromising awareness regarding the impact of their behaviors on the environment. This observation indicates that families should be supported and reassured that sharing financial information, particularly with children, does not compromise other responsibilities within the household. The system could reassure parents that it is beneficial to include their children in the discussion about the energy-related expenses as a part of defining family context. A recent view from Woodruff et al. (2008) highlights that in order to understand how eco-friendly behaviors are shaped in a domestic setting it is important to relate pro-environmental motivations to basic human needs such as physiological needs (providing for the basic resources for family members to have food and rest) and safety needs (have employment and financial security, comfort and a secure home) (Maslow, 1943). We argue that information about energy consumption should address different levels of awareness about energy consumption information as well as higher level needs (beliefs and values related to the need to be perceived as protective of the environment) in order to avoid jeopar- dizing basic family needs - safety (secure and comfort environment) and physiological ones (food and rest).

The study revealed that families' motivations for pro-environmental behaviors may vary substantially from those of individuals. In fact we found new motivations specific to families that had not been reported before in the literature: parenting, self and family identity and finally sense of control. More specifically, we found three variables -established routines, children age, and parental responsibilities to be a key in understanding families' latent motivations for pro-environmental behaviors.

Established routines in the household were found to shape whether and how families adopted the changes in their energy consumption. Families were more focused on completing their household daily tasks rather than considering if they were sustainable or even saving resources. On the other hand, families seem to lack awareness regarding how daily routines affect their flexibility to perform systemic behavior changes, which suggests that they tend to underestimate the effort, space and resources required 
for enabling a behavioral change. This highlights the constraints families deal with on a daily basis and points at their need for a sense of control in managing household chores such as meals, laundry, and driving children to school (Woodruff et al., 2008). These findings support Davidoff's et al. (2006) claim that ecodomestic technologies need to consider an organic evolution of routines and plans.

We further found that different family types reveal different motivations. For instance, the presence as well as the age of children influences the salience of different motivations. Our study highlighted the role of parenting in engaging with eco-friendly behaviors, and how such a role varies depending on children's age. Motivations of parents with younger children seemed to arise from moral values, such as education, discipline, identity and ideals. They showed an interest in educating children to be responsible citizens and to focus on long-term goals materialized through supervision of the acquisition of knowledge and habits as seen in Gronhoj (2006). On the contrary, for parents with older children, motivations were rooted in their need for managing the family budget and short-term goals, such as asking children to avoid using multiple devices simultaneously (e.g., a TV and a personal computer) but, at the same time, not verifying whether they followed these orders. Designing systems to support the adoption of sustainable behaviors should, therefore, support parents with respect to their changing roles and responsibilities, helping them to become role models to follow. The system could become a place that combines useful strategies to improve family consumption practices with values they want to transpose onto their children. Contrary, in households with children of age 10 or older, parents shared that they had difficulties communicating with their children when calling their attention to change their behaviors. Similarly to GramHassen (2007), parents revealed difficulties educating teenagers on eco-friendly behaviors due to the developmental challenges of that particular age. Interestingly, while this user group was the group that registered the highest levels of energy consumption, they were the ones who also had the highest level of interaction with the system. This suggests that despite the social challenges in achieving behavior change, this is a group where eco-feedback systems have the potential to involve all family members and raise their overall interest.

Contrary to previous studies (Dillahunt et al., 2009; Pierce, Schiano, et al., 2010; Strengers, 2011), we found individual motivations to be largely affected by the type and needs of the family. For example, families tried to adopt sustainable behaviors because they wanted to feel in control of their consumption, its costs but also, importantly, their lives. This can be seen as a core psychological need to feel safe and in control of one's life (Hassenzahl, Diefenbach, \& Goritz, 2010; Maslow, 1943; Sheldon, Elliot, Kim, \& Kasser, 2001). When designing for families in order to give them more control over their lives it is important to look at them as a collection of individuals with shared activities, schedules and routines. In other words, it is crucial to integrate family dynamics into the planning and monitoring of their energy consumption and sustainable actions (Costanza, Ramchurn, \& Jennings, 2012). By designing systems that provide easy ways to keep track of their current consumption, family members could gain a greater control by understanding how their behaviors impact the energy bill. A similar result could be achieved by allowing family members to define limits and goals they want to accomplish with respect to eco-friendly behaviors. As they explore the system, suggestions could be presented to assure that they meet these goals.

Finally a motivation that was not previously found at the individual level referred to self and family identity, which showed to tap into motivations of family members, either associated with practices learnt from previous generations or lifestyle ideals (like, for example, avoiding wasting energy because this is something one cares about). The study discovered certain conflicts among family members, which referred to inconsistencies between goals and actual behaviors to complete those goals or even criticisms of how they used specific devices, as for example: family members who would be report cost to be a concern but then would not be careful about their daily behavior, for instance would turn on the television in different household divisions even if alone at home. This suggests the existence of incompatible goals and needs of individual members and the family as a group. Therefore, ecofriendly systems should support expectations' negotiation among the family members through connecting individual motivations to the family core aspirations. Such systems could help to determine, which rules families want to maintain and which to discard. For example, a system could support families in transferring habits learned from previous generations in order for their children to be introduced to the desired family identity. It could be achieved by demonstrating the efforts their ancestors had to make in order to have clean water or energy in their homes. Additionally, the systems could suggest ways the behaviors in the family could be adopted without compromising current needs, the environment and even respect their family's identity, as a result of what they learned from their ancestors practices.

This research raises a number of questions:

Families integrate diversified interests, which are reflected in the motivations and actual energy consumption management. First, how can we design systems that combine conflicting motivations among different family members? Systems need to only to have the intelligence in inferring the latent motivations of use, but also the flexibility to accommodate the complex and dynamic routines and goals of usage within families.

This paper inquired into families' motivations for pro-environmental behaviors through interviewing 15 families who had been exposed to an eco-feedback interface over the period of 2 years. We found new motivations not reported before, associated with the need for parents to educate, set the example or even exercise discipline on their children by enforcing sustainable behaviors. In addition, we found families build their own identity based on cultural references and behaviors they learnt from previous generations. Furthermore we found families are motivated to learn more about their energy consumption practices in order to feel in control in reducing their utility bills.

We showed that motivations were influenced by the type of family, namely, household size, age of children or not having children at all. In addition to the type of family, priorities and immediate needs defined how such motivations were translated into actions, which ones were pursued and how flexible family members were to change such practices. For instance, motivations were established not only with respect to environmental concerns or financial motivations, but also as a way to achieve individual sense of control and security, enhance parents' perceived parental roles and responsibilities as well as reinforce family identity. As stated previously, families face complex challenges in terms of behavior change. Sustainable behaviors require from them the negotiation of expectations that might become contradictory with the individual motivations. Perceiving how such differences impacted their daily routine provided a number of guidelines to be appropriated when designing systems supporting behavior change in the context of sustainability.

\section{References}

Abrahamse, W., Steg, L., Vlek, C., \& Rothengatter, T. (2005). A review of intervention studies aimed at household energy conservation. Journal of Environmental Psychology, 25(3), 273-291.

Belk, R. (1988). Possessions and the extended self. Journal of Consumer Research, 15(2). 
Beyer, H., \& Holtzblatt, K. (1998). Contextual design: Defining customer-centered systems. Morgan Kaufman.

Black, R. I., \& Cherrier, H. (2010). Anti-consumption as part of living a sustainable lifestyle: Daily practices, contextual motivations and subjective values. Journal of Consumption Behavior, 9(4), 437-453.

Broms, L., Katzeff, C., Bang, M., Nyblom, A., Hjelm, S. I., \& Ehrnberger, K. (2010). Coffee maker patterns and the design of energy feedback artifacts. Paper presented at the proceedings of the 8th ACM conference on designing interactive systems, Arhus, Denmark.

Brynjarsdóttir, H., Hakansson, M., Pierce, J., Baumer, E. P. S., DiSalvo, C., \& Sengers, P. (2012). Sustainably unpersuaded: How persuasion narrows our vision of sustainability. Paper presented at the proceedings of the 2012 ACM annual conference on human factors in computing systems, Austin, Texas.

Chetty, M., Tran, D., \& Grinter, R. (2008). Getting to green: Understanding resource consumption in the home. Paper presented at the proceedings of the 10th international conference on ubiquitous computing, Seoul, Korea.

Costanza, E., Ramchurn, S. D., \& Jennings, N. R. (2012). Understanding domestic energy consumption through interactive visualisation: A field study. Paper presented at the proceedings of the 2012 ACM conference on ubiquitous computing, Pittsburgh, USA.

Davidoff, S., Ziebart, B. D., Zimmerman, J., \& Dey, A. (2011). Learning patterns of pick-ups and drop-offs to support busy family routines. Paper presented at the proceedings of the 2011 annual conference on human factors in computing systems, Vancouver, Canada.

Davidoff, S., Lee, M. K., Yiu, C., Zimmerman, J., \& Dey, A. K. (2006). Principles of smart control. UbiComp 2006: Ubiquitous Computing, 19-34.

Dillahunt, T., Mankoff, J., Paulos, E., \& Fussel, S. (2009). It's not all about "green": Energy use in low-income communities. Paper presented at the proceedings of the 11th international conference on ubiquitous computing, Orlando, Florida.

Elias, E. W. A., Dekoninck, E. A., \& Culley, S. J. (2007). The potential for domestic energy savings through assessing user behaviour and changes in design. In EcoDesign 2007 5th international symposium on environmentally conscious design and inverse manufacturing. Tokyo.

Fransson, N., \& Garling, T. (1999). Environmental concern: Conceptual definitions, measurement, methods and research findings. Journal of Environmental Psychology, 19, 369-382.

Froehlich, J. (2009). Promoting energy efficient behaviors in the home through feedback: The role of human-computer interaction. Paper presented at the proceedings of HCIC 2009 winter workshop boaster paper.

Froehlich, J., Findlater, L., \& Landay, J. A. (2010). The design of eco-feedback technology. Paper presented at the proceedings of the SIGCHI conference on human factors in computing systems, Atlanta, USA.

Froehlich, J., Findlater, L., Ostergren, M., Ramanathan, S., Peterson, J., Wragg, I. et al. (2012). The design and evaluation of prototype eco-feedback displays for fixture-level water usage data. Paper presented at the proceedings of the 2012 ACM annual conference on human factors in computing systems, Austin Texas.

Gilg, A., Barr, S., \& Ford, N. (2005). Green consumption or sustainable lifestyles? Identifying the sustainable consumer. Futures, 37(6), 481-504.

Gram-Hassen, K. (2007). Teenage consumption of cleanliness: How to make it sustainable? Sustainability: Science, Practice \& Policy, 3(2), 15-23.

Gronhoj, A. (2006). Communication about consumption: A family process perspective on 'green' consumer practices. Journal of Consumer Behavior, 5 , 491-503.

Hassenzahl, M., Diefenbach, S., \& Goritz, A. (2010). Needs, affect, and interactive products - Facets of users experience. Interacting with Computers, 22(5), 353-362.

Hazas, M., Brush, A., \& Scott, J. (2012). Sustainability does not begin with the individual. Interactions, 19(5), 14-17.

Hazas, M., Friday, A., \& Scott, J. (2010). Look back before leaping forward: Four decades of domestic energy inquiry. IEEE Magazine, 1.

He, H. A., Greenberg, S., \& Huang, E. M. (2010). One size does not fit all: Applying the transtheoretical model to energy feedback technology design. Paper presented at the proceedings of the 28th international conference on human factors in computing systems, Atlanta, USA.

Horn, M. S., Davis, P., Hubbard, A. K., Keifert, D., Leong, Z. A., \& Olson, I. C. (2011) Learning sustainability: Families, learning, and next-generation eco-feedback technology. Paper presented at the proceedings of the 10th international conference on interaction design and children, Michigan, USA.

Hsieh, H., \& Shannon, S. (2005). Three approaches to qualitative content analysis. Qualitative Health Research, 15(9), 1277-1288.
International, Q. (2012). NVivo qualitative research software. <http:// www.qsrinternational.com/products_nvivo.aspx>.

Kappel, K., \& Grechenig, T. (2009). "Show-me": Water consumption at a glance to promote water conservation in the shower. Paper presented at the proceedings of the 4th international conference on persuasive technology, California, USA.

Kjeldskov, J., Skov, M., Paay, J., \& Pathmanathan, R. (2012). Using mobile phones to support sustainability: A field study of residential electricity consumption. Paper presented at the proceedings of the 2012 ACM annual conference on human factors in computing systems, Austin, Texas.

Maslow, A. (1943). A theory of human motivation. Psychological Review, 50(4), 370.

Miller, W., \& Buys, L. (2010). Householder experiences with resource monitoring technology in sustainable homes. Paper presented at the proceedings of the 22nd conference of the computer-human interaction special interest group of Australia on computer-human interaction, Melbourne Australia.

Neustaedter, C., Bartram, L., \& Mah, A. (2013). Everyday activities and energy consumption: How families understand the relationship. Paper presented at the proc. CHI'13, Paris, France.

Odom, W., Pierce, J., Stolterman, E., \& Blevis, E. (2009). Understanding why we preserve some things and discard others in the context of interaction design. Paper presented at the proceedings of the SIGCHI conference on human factors in computing systems, Boston, USA.

Petkov, P., Köbler, F., Foth, M., \& Krcmar, H. (2011). Motivating domestic energy conservation through comparative, community-based feedback in mobile and social media. Paper presented at the proceedings of the 5th international conference on communities and technologies, Brisbane, Australia.

Petkov, P., Goswani, S., Kobler, F. \& Kremar, H. (2012). Personalised Eco-Feedback as a design technique for motivating energy saving behavior at home. Paper presented at the proceedings of the 7th Nordic conference on human-computer interaction: Making sense through design, Copenhagen Denmark.

Pierce, J., Fan, C., Lomas, D., Marcus, G., \& Paulos, E. (2010). Some consideration on the (in) effectiveness of residential energy feedback systems. Paper presented at the proceedings of the 8th ACM conference on designing interactive systems, Arhus, Denmark.

Pierce, J., Schiano, D. J., \& Paulos, E. (2010). Home, habits, and energy: Examining domestic interactions and energy consumption. Paper presented at the proceedings of the 28th international conference on human factors in computing systems, Atlanta, USA.

Riche, Y., Dodge, J., \& Metoyer, R. A. (2010). Studying always-on electricity feedback in the home. In Proceedings of the 28th international conference on human factors in computing systems (pp. 1995-1998)

Schäfer, M., \& Bamberg, S. (2008). Breaking habits: Linking sustainable consumption campaigns to sensitive life events. In Proceedings sustainable consumption and production: Framework for action, conference of the sustainable consumption research exchange (pp. 213-228).

Sheldon, K. M., Elliot, A. J., Kim, Y., \& Kasser, T. (2001). What is satisfying about satisfying events? Testing 10 candidate psychological needs. Journal of Personality and Social Psychology, 80(2), 325-339.

Shove, E. (2010). Beyond the ABC: Climate change policy and theories of social change. Environment and Planning A, 42(6), 1273-1285.

Steg, L. (2008). Promoting household energy conservation. Energy Policy, 36(12), 4449-4453.

Strengers, Y. (2011). Designing eco-feedback systems for everyday life. Paper presented at the proceedings of the 2011 annual conference on human factors in computing systems, Vancouver, Canada.

Tan, Y. (2009). Persuasive technology in motivating household energy conservation (pp. 52-58). Zurich FS ETH Zurich.

Thieme, A., Comber, R., Miebach, J., Weeden, J., Kramer, N., Lawson, S., et al. (2012). "We've bon watching you" - designing for reflection and social persuasion to promote sustainable lifestyles. Paper presented at the proceedings of the 2012 ACM annual conference on human factors in computing systems, Austin, Texas.

Watterson, J., \& Fernandez, R. (2012). End-user GHG emissions from energy: Reallocation of emissions from energy industries to end users 2005-2010. European Environment Agency (EEA).

Wilson, C., \& Dowlatabadi, H. (2007). Models of decision making and residential energy use. Annual Review of Environment and Resources, 169-203.

Woodruff, A., Hasbrouck, J., \& Augustin, S. (2008). A bright green perspective on sustainable choices. Paper presented at the proceedings of the SIGCHI conference on human factors in computing systems, Florence, Italy.

Zimmerman, J. (2009). Designing for the Self: Making products that help people become the person they desire to be. Paper presented at the proceedings of the SIGCHI Conference on human factors in computing systems, Boston, USA. 